\title{
ФИЗИЧЕСКИЕ МЕТОДЫ В ЛЕЧЕНИИ ПАЦИЕНТОВ С ПРОЯВЛЕНИЯМИ КРАСНОГО ПЛОСКОГО ЛИШАЯ НА СЛИЗИСТОЙ ОБОЛОЧКЕ ПОЛОСТИ РТА
}

\section{PHYSICAL METHODS IN THE TREATMENT OF PATIENTS WITH MANIFESTATIONS OF LICHEN PLANUS ON THE ORAL MUCOSA}

O. Serikova

Summary. Lichen planus is classified as a chronic recurrent dermatosis with unspecified etiopathogenesis, a variety of trigger factors, a severe, often permanent course, a tendency to malignancy of the lesion elements, and refractoriness to treatment. The development of effective methods for the treatment of severe forms of lichen planus of the oral mucosa, refractory to corticosteroids, is an important clinical problem. The inclusion in the complex treatment of such methods as ozone therapy and photophoresis in patients with manifestations of lichen planus on the oral mucosa allowed the author to accelerate the timing of epithelization of erosive and ulcerative elements and achieve stable remission of the disease. Positive results of treatment of 85 patients allowed us to recommend the use of physical methods in the complex therapy of manifestations of lichen planus on the oral mucosa.

Keywords: oral mucosa, lichen planus, physiotherapy, ozone therapy, photophoresis.

\section{Введение}

$\mathbf{K}$ расный плоский лишай (хронический рецидивирующий дерматоз с неуточненным сложным этиопатогенезом) многие специалисты рассматривают как мультифакторное заболевание, при котором эндогенные и экзогенные факторы могут играть определенную роль в формировании, характере течения и исходе патологического процесса $[1,2,3,4,5]$. Слизистая оболочка рта - наиболее частая локализация заболевания.

Актуальными задачами являются поиск и разработка таких новых методов лечения красного плоского лишая слизистой оболочки рта, которые характеризовались бы высокой эффективностью, малым количеством осложнений и побочных явлений, обеспечивая длительную ремиссию заболевания.

\author{
Серикова Ольга Васильевна \\ К.м.н., ассистент, Воронежский государственный \\ медицинский университет им. Н.Н. Бурденко \\ natasable@yandex.ru
}

Аннотация. Красный плоский лишай классифицируют как хронический рецидивирующий дерматоз с неуточненным этиопатогенезом, многообразием триггерных факторов, тяжелым, часто перманентным течением, тенденцией к озлокачествлению элементов поражения, рефрактерностью к проводимому лечению. Разработка эффективных методик лечения тяжелых форм красного плоского лишая слизистой оболочки рта, рефрактерных к кортикостероидам, является важной клинической проблемой. Включение в комплексное лечение таких методов, как озонотерапия и фотофорез у пациентов с проявлениями красного плоского лишая на слизистой оболочке рта, позволило автору ускорить сроки эпителизации эрозивно-язвенных элементов и добиться стойкой ремиссии заболевания. Положительные результаты лечения 85 пациентов позволили рекомендовать к использованию физические методы в комплексной терапии проявлений красного плоского лишая на слизистой оболочке рта.

Ключевые слова: слизистая оболочка рта, красный плоский лишай, физиотерапия, озонотерапия, фотофорез.

Активное совершенствование немедикаментозных способов терапии красного плоского лишая (КПЛ) слизистой оболочки рта (СОР) приобрело особенно большое значение в связи с возрастанием побочных эффектов, противопоказаний и токсико-аллергических реакций при применении различных медикаментозных средств, используемых в лечении данного заболевания.

Анализ приоритетов развития современной медицины свидетельствует о неуклонном возрастании удельного веса лечебных физических факторов в структуре видов медицинской помощи. Подтверждением этого явилось включение методов физиотерапии в стандарты оказания первичной медико-санитарной помощи в соответствии со статьей 37 Федерального закона от 21 ноября 2011 г. № 323-Ф3 «Об основах охраны здоровья граждан в Российской Федерации» у больных с различной патологией [6]. 
В научной литературе имеются многочисленные данные о применении различных физических методов в лечении КПЛ, в том числе слизистой оболочки рта. Однако, учитывая тот факт, что большинство больных КПЛ СОР имеют в анамнезе коморбидную патологию (сердечно-сосудистую, эндокринную и другие), применение многих физических факторов в программе лечения ограничено определенными противопоказаниями к их использованию [7].

В связи с этим возникает необходимость поиска новых простых, доступных и безопасных методов лечения с минимальным количеством побочных эффектов и противопоказаний при тяжелых формах КПЛ СОР.

Физические методы лечения, как правило, способны не только исключить или существенным образом сократить потребность в применении различных лекарственных препаратов системного действия, но, и, воздействуя на различные звенья патологического процесса, способствовать регуляции нарушенного гемостаза, активации защитных сил организма $[6,8,9]$.

Перспективным направлением комплексного, с использованием физиотерапии, лечения пациентов с проявлениями красного плоского лишая на слизистой оболочке рта является использование озона. Озонотерапия оказывает антибактериальное, противовирусное, фунгицидное, противовоспалительное, иммуномодулирующее, цитостатическое и анальгезирующее действие. Низкие концентрации озона способствуют эпителизации и заживлению раневых поверхностей $[10,11]$

Альтернативным физическим фактором, активно применяющимся в медицине, является свет различной длины волны. Заслуживают внимания разработанные в последние годы источники светодиодного излучения красного цвета (СДИКЦ), работа которых основана на применении «мягкого» воздействия на биологические ткани. Красный свет от светодиодов в физиотерапевтических аппаратах и лампах имеет достаточно большую плотность мощности излучения, поэтому в механизме лечебного действия его можно сравнивать с красным лазерным излучением. Достоверно установлена сопоставимость биологического и клинического эффекта лазерного излучения и некогерентного монохроматического света $[12,13$, 14].

Многие ученые отмечают, что применение светотерапии в сочетании с медикаментозными препаратами (фотофорез), производя минимальный повреждающий эффект и оказывая явную пользу в лечении аутоиммунных заболеваний, демонстрирует четкие преимуще- ства по сравнению с химиотерапевтическими методами и использованием иммунодепрессантов [15].

В последнее время актуализируются перспективы комплексного воздействия различными физическими факторами - в сочетании или комбинированно. Комбинированная физиотерапия представляет последовательное (разновременное) воздействие физическими факторами в течение одного курса лечения. Сочетанное и комбинированное использование физических факторов (или сочетанная физиотерапия) получило в последнее время бурное развитие в медицине, а разработка таких новых методов физиотерапии является одним из перспективных путей оптимизации и развития физических методов лечения $[16,17,18,19]$.

\section{Цель исслеАования}

Повышение качества лечения пациентов с проявлениями красного плоского лишая на слизистой оболочке рта на основе применения физических методов в комплексной терапии.

\section{Материалы и методы исследования}

Для достижения поставленной цели исследования клинические наблюдения были выполнены у 85 пациентов с проявления тяжелого течения осложненных форм красного плоского лишая на слизистой оболочке рта.

Критерии определения тяжелого течения осложненных форм КПЛ на СОР включают следующие фактоpы:

1. осложненные экссудативно-гиперемическая или эрозивно-язвенная формы заболевания;

2. степень выраженности боли от 4-7 баллов по визуально-аналоговой шкале (ВАШ);

3. непрерывно-рецидивирующий характер течения (обострение заболевания в пределах одного месяца после окончания лечения).

4. резистентность к проводимому традиционному лечению;

5. сумма баллов по шкале оценки качества жизни пациентов с проявлениями заболевания в полости рта OHIP-14 более 20.

Внутриструктурный анализ проявлений КПЛ на СОР показал, что тяжелое непрерывно-рецидивирующего течение осложненных форм диагностировано у 85 пациентов. Чаще подобный вариант течения отмечался при эрозивно-язвенной форме заболевания (50 человек, 58,8\% от числа больных тяжелой формой КПЛ), экссудативно-гиперемическая форма при тяжелом течении была выявлена у 35 лиц (41,2\%). Среди пациентов, 
страдающих тяжелым течением проявлений осложненных форм болезни, преобладали лица женского пола 79 (93,0\%) пациентов. Лица мужского пола составили 6 человек $(7,0 \%)$ среди обследованных пациентов.

Данные, полученные в результате обследования больных, вносились автором в специальные, успешно апробированные на практике, индивидуальные карты-вкладыши больных с заболеваниями СОР (первичный и повторный осмотр), подтвержденные рацпредложением № 1607 от 07.04.16.

В зависимости от комплекса проводимых лечебных процедур все пациенты с тяжелым течением проявлений заболевания были распределены на 4 группы:

- I группа (контрольная) включала 22 человека, в том числе 20 женщин в возрасте от 45 лет до 75 и двух мужчин 48 и 65 лет, которым проводили традиционное медикаментозное лечение;

- II группа основная включала 21 человека, в том числе 20 женщин в возрасте от 47 до 74 лет и одного мужчину 63 лет, которым проводили комплексное лечение с применением озонотерапии, используя аппарат «Prozone» австрийской фирмы «W\&H»;

- III группу основную составили 20 лиц, в том числе 18 женщин в возрасте от 40 лет до 70 и двое мужчин 56 и 72 лет, которые получали комплексное лечение с применением фотофореза светодиодного излучения красного цвета (СДИКЦ) и высокоактивного топического стероида (Адвантан);

- IV группа основная включала 22 пациента, в том числе 20 женщин в возрасте от 45 лет до 75 и двух мужчин 55 и 69 лет, которым проводилось комплексное лечение с применением комбинированной физиотерапии (озонотерапия и фотофорез).

В каждой группе были выделены две подгруппы в соответствии с клиническими формами заболевания: подгруппа А с проявлениями эрозивно-язвенной (ЭЯФ) формы КПЛ, подгруппа В с проявлениями экссудативно-гиперемической (ЭГФ) формы КПЛ.

Выделенные группы пациентов были сопоставимы по возрасту, полу, показателям общесоматического здоровья и формам заболевания.

Эффективность физических методов в комплексной терапии тяжелых форм КПЛ СОР и ККГ оценивали по следующим параметрам: динамика болевых ощущений в полости рта по визуально-аналоговой шкале боли (ВАШ); изменение симптомов воспаления СОР (наличие отека и гиперемии); сроки эпителизации эрозивно-язвенных элементов; осложнения от применяемого лечения.

\section{Результаты исслеАования \\ и их обсужАение}

В процессе комплексной терапии больных с тяжелыми формами КПЛ СОР положительные изменения клинической картины были отмечены во всех группах исследования.

Если до лечения все больные тяжелыми формами КПЛ предъявляли жалобы на интенсивные болевые ощущения (4-5 баллов по ВАШ) и чувство жжения в полости рта, то под влиянием комплексного лечения на 5-й день интенсивность боли и жжения резко снизились во всех группах.

Комплексное лечение с использованием физических методов способствовало не только снижению или полному купированию болевых ощущений и жжения у пациентов, но и уменьшению остроты симптомов воспаления СОР, проявлявшихся в виде отека и гиперемии слизистой оболочки у 100\% больных тяжелыми формами КПЛ СОР и до лечения.

Наиболее выраженный противовоспалительный эффект оказывает лечение КПЛ СОР комбинированной физиотерапией с использованием озона и фотофореза топических стероидов (подгруппы IVA и IVB), что выражалось в устранении воспалительной реакции слизистой оболочки в более короткие сроки и у большей доли больных по отношению к группе сравнения и группам исследования II и III.

Физические методы в комплексном лечении тяжелых формам КПЛ СОР способствовали стимуляции регенерации слизистой оболочки в очагах поражения при ЭЯФ, что проявлялось уменьшением эрозивно-язвенных очагов и эпителизацией патологических элементов. Динамику процессов регенерации оценивали по уменьшению размеров язв и эрозий в процессе лечения, процессу и срокам их окончательной эпителизации, изменению цитологических показателей.

На пятые сутки лечения средние размеры дефектов уменьшились до 50\% от исходного состояния, на 7-8 сутки - до 35\%, на 10-12 сутки - до $10 \%$.

Динамика процесса заживления эрозивно-язвенных элементов СОР в группах исследования оценивалась по количеству больных с признаками эпителизации при контрольных осмотрах.

При осмотре по окончании курса терапии через 30 дней полная эпителизация патологических элементов СОР была установлена у 9 человек $(75,0 \%)$ в группе 
IA, у 13 (100\%) пациентов в группе IIA, у 11 пациентов (100\%) в группе IIIA, у 12 человек (100\%) в группе IVA.

Процесс эпителизации эрозивно-язвенных элементов при ЭЯФ у больных с тяжелыми формами КПЛ СОР и ККГ наиболее активно протекал при использовании В комплексном лечении комбинированной физиотерапии (озонотерапия и фотофорез топических стероидов). Заживляющий эффект комбинированной физиотерапии был особенно выражен при одиночных эрозиях и язвах на слизистой оболочке рта и красной кайме губ.

Сокращение сроков эпителизации отмечено в группах II, III и особенно IV (подгруппы A) по сравнению с группой сравнения (IA). Таким образом, применение физических методов в комплексном лечении КПЛ СОР способствует ускорению заживления эрозивно-язвенных элементов при тяжелых формах КПЛ СОР. В группе ІА у трех больных с генерализованным поражением СОР (вовлечение в патологический процесс более трех зон поражения (ОР) полная эпителизация всех эрозивно-язвенных элементов не наступила.

Все пациенты хорошо переносили физические методы лечения. Побочных явлений во время и после проведения процедур не наблюдалось.

Для оценки результатов лечения использовали следующие критерии:

- «ремиссия» - полный регресс клинических проявлений КПЛ СОР;

- «значительное улучшение» - это трансформация экссудативно-гиперемической формы в типичную, а эрозивно-язвенной - в экссудативно-гиперемическую;
- «улучшение» - сокращение размеров эрозий и уменьшение воспалительных явлений;

- «без эффекта» - сохранение воспалительных явлений и эрозивно-язвенных элементов на слизистой оболочке рта и красной каймы губ и субъективных ощущений (болезненность, невозможность приема пищи).

- «ухудшение» - увеличение числа и размеров элементов поражения СОР, усиление субъективных ощущений, переход в более тяжелую форму.

Состояние ремиссии, значительного улучшения и (или) улучшения оценивали, как положительный терапевтический эффект. Состояния «без эффекта» и «ухудшение» ни у одного больного из всех групп наблюдения не было выявлено.

Наилучшие результаты лечения тяжелых форм КПЛ СОР получены при использовании комбинированной физиотерапии в подгруппах IVA, IVB.

\section{Зак^ючение}

Таким образом, положительная динамика клинической картины в процессе лечения обосновывает целесообразность включения физических методов в схему терапии пациентов с тяжелыми проявлениями КПЛ на слизистой полости рта. Наилучший клинический эффект наблюдался у больных с экссудативно-гиперемической формой КПЛ СОР в группе, где в комплексное лечение была включена комбинированная физиотерапия (озон и фотофорез топических стероидов), что позволяет рекомендовать данную методику для внедрения в клиническую практику.

\section{ЛИТЕРАТУРА}

1. Молочков В.А., Сухова Т.Е., Молочкова Ю.В. Клинические особенности красного плоского лишая //Клиническая дерматология и венерология. 2013. № 4. С. 34-42.

2. Дерматовенерология: национальное руководство / Ассоциация медицинских обществ по качеству; под редакцией: Ю.К. Скрипкина, Ю.С. Бутова, 0.Л. Иванова. Москва: ГЭОТАР-Медиа, 2020.896 с. ISBN978-5-9704-2051-5.

3. Лукиных Л.М., Тиунова Н.В. Современные представления об этиопатогенезе красного плоского лишая слизистой оболочки полости рта // Современная стоматология. 2013. Т. 57, № 2. С. 18-20.

4. Рабинович 0.Ф., Рабинович И.М., Бабиченко И.И. Красный плоский лишай слизистой оболочки рта. Москва: Российская академия наук, 2018.80 с. ISBN978-5-906906-36-6.

5. Заболевания слизистой оболочки полости рта: методы диагностики и лечения / 0.С. Гилева [и др.] // Dental Forum. 2019. № 1 (72). С. $27-36$.

6. Физическая и реабилитационная медицина. Национальное руководство / Г.Н. Пономаренко, П.В. Антипенко, Г.Р. Абусева; под редакцией Г.Н. Пономаренко. Москва: ГЭОТАР-Медиа, 2020. 688 с. (Серия «Национальные руководства»). ISBN978-5-9704-1184-1.

7. Коморбидность при красном плоском лишае / Н.А. Слесаренко [и др.] // Клиническая дерматология и венерология. 2014. № 5. С. 4-10.

8. Блашкова С.Л., Фазылова Ю.В. Особенности гигиенического ухода у пациентов с проявлениями дерматозов на слизистой оболочке рта // Пародонтология. 2018. Т. 23, № 2 (87). С. 53-57.

9. Абрамович С.Г. Фототерапия. Иркутск: РИО ФГБУ «НЦРВХ» СОРАМН, 2014. 200 с. ISBN978-5-98277-172-8.

10. Орехова Л.Ю. Клинический опыт применения озонотерапии в комплексном лечении воспалительных заболеваний пародонта // Пародонтология. 2013. № 3: C. 41-45. 
11. Dvorak V. Использование озона в стоматологии // Новое в стоматологии. 2005. № 5. С. 82-86.

12. Лесных Н.И., Кунин В.А. Применение низкоинтенсивного лазерного излучения и монохроматического красного света для лечения воспалительных состояний слизистой оболочки полости рта и пародонта в клинике ортопедической стоматологии: методические рекомендации. Воронеж, 2004.22 с.

13. Применение модулированного красного света в клинике ортопедической стоматологии на этапе адаптации тканей протезного ложа к изготовленным съёмным зубным протезам / В.А. Кунин [и др.] // Стоматология славянских государств: труды VII Международной научно-практической конференции. Белгород: ИД «Белгород» НИУ «БелГУ», 2014. С. 197-201.

14. Jajarm H., Falaki F., Mahdavi 0. A comparative pilot study of low intensity laser versus topical corticosteroids in the treatment of erosive-atrophic oral lichen planus // Photomed. Laser Surg. 2011. V. 29 (6): P. 421-425. https://www.liebertpub.com/ doi/10.1089/pho.2010.2876.

15. Efficacy of laser phototherapy in comparison to topical clobetasol for the treatment of oral lichen planus: a randomized controlled trial / C.S. Dillenburg [et al.] // Journal of biomedical optics. 2014. Vol. 19, № 6. P. 68. https://doi.org/10.1117/1.JB0.19.6.068002.

16. Улащик В.С. Физиотерапия. Новейшие методы и технологии: справочное пособие. Минск: Книжный Дом, 2013. 446 c. - ISBN978-985-17-0635-4.

17. Миненков А.А. Сочетание физических факторов при различных заболеваниях: пособие для врачей. // Вопросы курортологии, физиотерапии и ЛФК. 2006. № 1. C. 47-51.

18. Elewa R., Altenburg A., Zouboulis C. Recalcitrant severe erosive cutaneous lichen planus treated with extracorporeal photopheresis monotherapy //Br. J. Dermatol. 2011. 165 (2). P: 441-443. https://doi.org/10.1111/j.1365-2133.2011.10378.x.

19. Комбинированная физиотерапия в лечении тяжелых форм красного плоского лишая слизистой оболочки рта / 0.В. Серикова [и др.] // Научные ведомости Белгородского государственного университета. Медицина. Фармация. 2019. № 42 (1). С. 91-98.

( С Серикова Ольга Васильевна ( natasable@yandex.ru ).

Журнал «Современная наука: актуальные проблемы теории и практики»

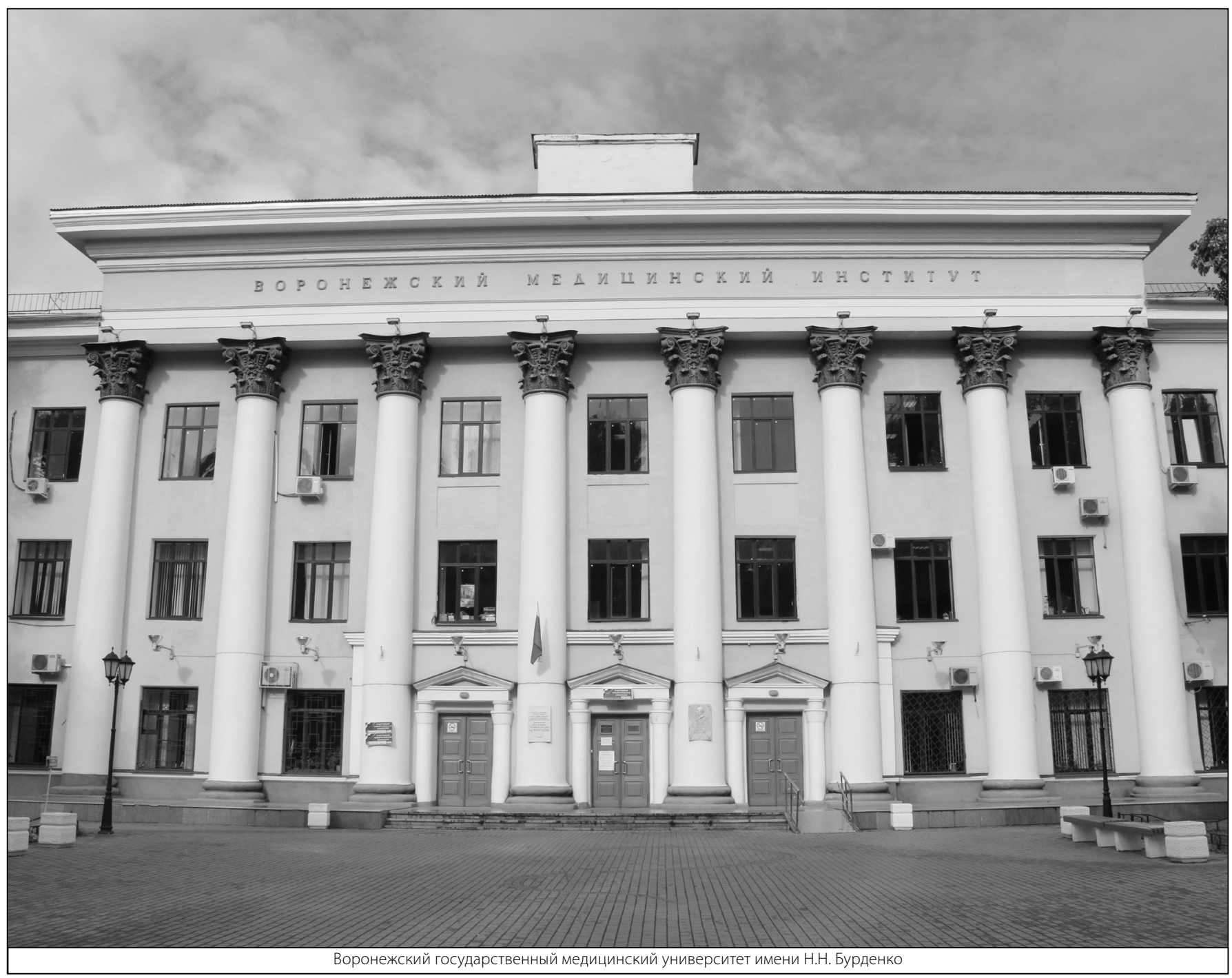

